\title{
Minimally invasive decompression versus open laminectomy for central stenosis of the lumbar spine: pragmatic comparative effectiveness study
}

\author{
Ulf S Nerland, ,, 2 Asgeir S Jakola, , 3, 4 Ole Solheim, , 2, 4 Clemens Weber, , 2, 5 Vidar Rao, , 2 \\ Greger Lønne, 2,6 Tore K Solberg, 7,8 Øyvind Salvesen, ${ }^{9}$ Sven M Carlsen, ${ }^{9,10}$ \\ Øystein P Nygaard, 1, 2,5 Sasha Gulati1, 2, 5, 11
}

For numbered affiliations see end of article.

Correspondence to: S Gulati Department of Neurosurgery, St Olavs University Hospital, 7006 Trondheim, Norway sashagulati@hotmail.com Cite this as: $B M J$ 2015;350:h1603 doi:10.1136/bmj.h1603

Accepted: 25 February 2015

\section{ABSTRACT}

\section{OBJECTIVE}

To test the equivalence for clinical effectiveness between microdecompression and laminectomy in patients with central lumbar spinal stenosis.

DESIGN

Multicentre observational study.

SETTING

Prospective data from the Norwegian Registry for Spine Surgery.

\section{PARTICIPANTS}

885 patients with central stenosis of the lumbar spine who underwent surgery at 34 Norwegian orthopaedic or neurosurgical departments. Patients were treated from October 2006 to December 2011.

\section{INTERVENTIONS}

Laminectomy and microdecompression.

\section{MAIN OUTCOME MEASURES}

The primary outcome was change in Oswestry disability index score one year after surgery. Secondary endpoints were quality of life (EuroQol EQ-5D), perioperative complications, and duration of surgical procedures and hospital stays. A blinded biostatistician performed predefined statistical analyses in unmatched and propensity matched cohorts.

\section{RESULTS}

The study was powered to detect a difference between the groups of eight points on the Oswestry disability index at one year. 721 patients (81\%) completed the one year follow-up. Equivalence between microdecompression and laminectomy was shown for the Oswestry disability index (difference 1.3 points, $95 \%$ confidence interval -1.36 to $3.92, \mathrm{P}<0.001$ for

\section{WHAT IS ALREADY KNOWN ON THIS TOPIC}

Evidence shows that surgical decompression for central lumbar spinal stenosis offers an advantage over non-surgical management for patients with persistent severe symptoms

Laminectomy has traditionally been the standard treatment in patients without instability, but in recent years less invasive procedures such as

microdecompression have emerged

The shift towards minimally invasive surgical methods has not been backed by solid evidence

\section{WHAT THIS STUDY ADDS}

The effectiveness of microdecompression is equivalent to laminectomy in the surgical treatment of central lumbar spinal stenosis equivalence). Equivalence was confirmed in the propensity matched cohort and full information regression analyses. No difference was found between groups in quality of life (EQ-5D) one year after surgery. The number of patients with complications was higher in the laminectomy group $(15.0 \%$ v $9.8 \%, \mathrm{P}=0.018)$, but after propensity matching for complications the groups did not differ $(\mathrm{P}=0.23)$. The duration of surgery for single level decompression was shorter in the microdecompression group (difference 11.2 minutes, $95 \%$ confidence interval 4.9 to $17.5, \mathrm{P}<0.001$ ), but after propensity matching the groups did not differ $(\mathrm{P}=0.15)$. Patients in the microdecompression group had shorter hospital stays, both for single level decompression (difference 1.5 days, 95\% confidence interval 1.7 to 2.6, $\mathrm{P}<0.001)$ and two level decompression (0.8 days, 1.0 to $2.2, \mathrm{P}=0.003$ ).

\section{CONCLUSION}

At one year the effectiveness of microdecompression is equivalent to laminectomy in the surgical treatment of central stenosis of the lumbar spine. Favourable outcomes were observed at one year in both treatment groups.

TRIAL REGISTRATION

ClinicalTrials.gov NCT02006901.

\section{Introduction}

Stenosis of the lumbar spine is a highly prevalent condition that often results from a gradual, degenerative aging process. ${ }^{1}$ The clinical syndrome of the stenosis is characterised by low back pain and pain and numbness in the legs, and it is a common source of impaired walking and disability in older people ( $\geq 60$ years). Sudden changes in symptomatology are uncommon, ${ }^{2}$ and an expectant or non-surgical approach is often chosen for patients with mild or moderate symptoms, with sparse motivation for surgery, or in whom the risk of surgery outweighs the potential benefits. ${ }^{3-5}$ Most patients with symptoms who are managed without surgery report no substantial change over the course of one year. ${ }^{6-8}$ Still, there is growing evidence that surgical decompression offers an advantage over non-surgical management for selected patients with persistent severe symptoms. ${ }^{346910}$ Consequently, lumbar spinal stenosis is the most common indication for spinal surgery in elderly people, and as the oldest sector of the population continues to grow the prevalence of the condition is likely to increase. ${ }^{11-13}$

Open laminectomy, often combined with medial facetectomy and foraminotomy, has traditionally been the 
standard treatment in patients without instability. ${ }^{13}$ In recent years less invasive procedures have emerged, ${ }^{14} 15$ and microdecompression through smaller incisions is frequently performed. As is often the case in surgery, the shift towards minimally invasive methods has not been backed by solid evidence. ${ }^{16}$ Except for a small and probably underpowered trial that reported promising results with bilateral microdecompression, no comparative studies have been performed. ${ }^{15}$ In the management of lumbar spinal stenosis it is essentially unknown if microdecompression is equivalent to the traditional laminectomy that it has replaced in many spine centres.

In this observational registry based equivalence study we compared clinical outcomes in patients with central stenosis of the lumbar spine treated with either open laminectomy or microdecompression.

\section{Methods}

Reporting is consistent with the strengthening the reporting of observational studies in epidemiology statement. ${ }^{17}$ The study was registered in ClinicalTrials. gov and the protocol published before the study was started. ${ }^{18}$

\section{Study population}

Norway has a public healthcare system with equal distribution of resources and uniform training and licensing of healthcare staff. The population is homogeneous and stable. In general the departments that participated in this study have one preferred surgical strategy for lumbar spinal stenosis without radiological instability. Patients are usually treated at the hospital serving their residential address, limiting referral bias.

We collected data through the Norwegian Registry for Spine Surgery (NORspine), a comprehensive registry for quality control and research. In total, 36 of 40 centres performing lumbar spine surgery in Norway report to the registry. NORspine is linked to the National Registry and Statistics Norway, which contain information on everyone who either is or has been a resident in Norway. According to the Norwegian Directorate of Health approximately $65 \%$ of all patients who undergo lumbar spine surgery in Norway are included in NORspine. The inclusion rate is presumably higher for lumbar spinal stenosis related surgery as most of these procedures are scheduled. Participation in the registration by providers or patients was not mandated, nor was participation required as a necessary condition for a patient to gain access to healthcare or for a provider to be eligible for payment. We screened patients who underwent surgery between October 2006 and December 2011 for eligibility. Follow-up time from the date of the operation was one year.

We considered patients to be eligible for the study if they had a diagnosis of central stenosis of the lumbar spine, surgery was at one or two lumbar levels with either open laminectomy or microdecompression, and their data were included in the NORspine registry. Patients were excluded who had undergone previous surgery of the lumbar spine, undergone discectomy as part of the decompression, or had associated spinal conditions (disc herniation, spondylolisthesis, or degenerative scoliosis).

\section{Outcome measures}

The primary outcome was change in disease specific functional outcome between baseline and 12 months' follow-up measured with version 2.0 of the Oswestry disability index, ${ }^{19}$ which has been translated into Norwegian and tested for psychometric properties. ${ }^{20}$ The Oswestry disability index questionnaire is used to quantify disability for degenerative conditions of the lumbar spine and covers intensity of pain, ability to lift, ability to care for oneself, ability to walk, ability to sit, sexual function, ability to stand, social life, sleep quality, and ability to travel. For each topic there are six statements describing potential scenarios, and patients select the one that most closely resembles their situation. The index is scored from 0 to 100 . Zero means no disability and 100 reflects maximum disability.

Secondary outcome measures were changes in generic health related quality of life, measured with the Euro-Qol-5D (EQ-5D) between baseline and 12-months' follow-up, perioperative complications, and duration of surgical procedures and hospital stays.

The Norwegian version of EQ-5D has shown good psychometric properties. ${ }^{21}$ Surgeons provided the following complications and adverse events to NORspine: intraoperative haemorrhage blood replacement or postoperative haematoma, unintentional durotomy, cardiovascular complications, respiratory complications, anaphylactic reactions, and wrong level for surgery. Patients reported the following complications if occurring within three months of surgery: wound infection, urinary tract infection, micturition problems, pneumonia, pulmonary embolism, and deep vein thrombosis.

\section{Data collection by NORspine}

On admission for surgery the patients completed the baseline questionnaire, which included questions about demographics and personal characteristics (marital status, education, body mass index, and smoking) in addition to the outcome measures. Using a standard registration form, surgeons recorded data on diagnosis, comorbidity (including rheumatic diseases, hip or knee osteoarthritis, depression or anxiety, musculoskeletal pain, neurological disorder, cerebrovascular disease, cardiovascular disease, vascular claudication, lung disease, cancer, osteoporosis, hypertension, endocrine disorders), American Society of Anesthesiologists grade, image findings, surgical procedure, and complications. NORspine distributed questionnaires to the patients by post three and 12 months after surgery. Non-responders received one reminder with a new copy of the questionnaire. The patients completed questionnaires without assistance from the surgeon.

\section{Diagnostic imaging}

The investigators of this study had access to all magnetic resonance imaging performed at all seven hospitals in the central Norway health region. Two authors 
(CW, VR) were blinded to treatment and together performed a morphological grading from A-D for the severity of the stenosis as described by Schizas and colleagues. ${ }^{22}$ They registered the grade of the most stenotic level for which surgery was performed.

\section{Surgical procedures}

When a laminectomy is performed, the spinous process and the laminas of the involved levels as well as the medial aspects of the facet joints are resected. ${ }^{15}$ Microdecompression through a smaller skin incision can be performed using a bilateral or unilateral approach depending on the surgeon's preference and the patient's anatomy and symptoms. Unlike with a laminectomy, the spinous process and the supraspinous and interspinous ligaments are left intact during a microdecompression. ${ }^{15}$ An operating microscope is used to perform microdecompression, whereas laminectomy procedures can be performed either with or without an operating microscope. Surgical techniques other than those previously described were not included in the study.

\section{Statistical analysis}

Statistical analyses were performed with SPSS 18.0 and Software R. ${ }^{23}$ The minimal clinically important difference for change in the mean Oswestry disability index score is considered to be in the range of $8-10$ points. ${ }^{24-26}$ The size of the study was based on a null hypothesis of non-equivalence and an alternative hypothesis of equivalence. If the population effect of treatment on changes is eight points or less, treatments are considered equivalent for effectiveness. The sample size calculation related to a two one sided test for equivalence, with a significance level of $2.5 \%$. We computed the $\mathrm{P}$ values for equivalence as 1 minus the maximum confidence level at which the confidence interval was contained in ( -8 to 8 ) divided by 2 giving the $P$ values of the two one sided test for equivalence. This applied to both the complete case analysis and the mixed linear model analysis in both the aggregate cohort and the propensity matched cohort. Assuming a correlation of 0.5 between baseline and follow-up measurements and a standard deviation of 18 for the individual measurements, the study would have 90\% power, with 132 patients in each group. For statistical comparison tests we defined the significance level as $\mathrm{P} \leq 0.05$ with no adjustments for multiple comparisons. For the primary outcome and one secondary outcome (EQ-5D) a statistician (ØS) blinded to treatment performed both a complete case analysis and a full information analysis using mixed linear models. In the mixed model patients were not excluded from the analysis if the variable was missing at some, but not all, time points after baseline. In the mixed linear model analysis of the aggregate cohort, we took the combination of treatment and time as the fixed factor (giving six levels for this covariate) and patient identity as the random effect. We used Wald type confidence intervals for linear contrasts of parameters. In the mixed linear model for the propensity matched cohort we assumed no treatment effect at baseline owing to the matching procedure. Furthermore, we included a random effect of pair identity to account for dependence introduced by the matching. The P values for the complete case analysis and mixed linear model analysis relate to 12 months' equivalence testing. We handled missing data with mixed linear models and did not perform multiple imputations. This strategy was in line with a study showing that it is not necessary to handle missing data using multiple imputations before performing a mixed model analysis on longitudinal data. ${ }^{27}$ In the additional analyses (categorical data at three months' follow-up), we did not replace missing data. To evaluate the magnitude of change in EQ-5D score, we estimated effect sizes according to the method of Kazis. ${ }^{28}$ An effect size of 0.8 or more is considered large. We conducted two prespecified subgroup analyses to compare the clinical effectiveness of microdecompression and laminectomy in elderly patients aged 70 years or more and in obese patients (body mass index $\geq 30$ ). ${ }^{18}$ Before statistical analyses we predefined the table and figure contents. We did not carry out additional exploratory statistical analyses.

\section{Analyses of aggregate cohort}

We analysed continuous variables using an unpaired two tailed $t$ test for normally distributed data and continuous data with skewed distribution using the Mann-Whitney $U$ test. A $x^{2}$ analysis was used to compare discrete variables. All tables were determined before any statistical procedure was undertaken, and no information was deleted when results were known.

\section{Analyses of the propensity matched cohort}

The matching approach technique of using propensity scores, as opposed to stratification or regression adjustment, was chosen because it is the closest approximate to a randomised clinical trial and provides the greatest balance between the two treatment groups. ${ }^{29} 30$ We generated propensity scores for surgical technique using logistic regression and adjusting for baseline covariates that could influence treatment outcomes, including age, sex, life partner, comorbidity, body mass index, smoking, educational level, number of operated levels, and preoperative Oswestry disability index score. All covariates were entered into a logistic regression analysis, and we fitted a maximum likelihood model based on these covariates as predictors of surgical technique. The coefficients for these predictors of surgical technique were used to calculate a propensity score of 0 to 1 for each patient. Based on the calculated propensity scores, two evenly matched groups were formed for surgical technique using a matching algorithm with the common caliper set at 0.010. This dataset is referred to as the "propensity matched cohort." We analysed continuous variables using a related samples two tailed $t$ test for data with a normal distribution and continuous data exhibiting a skewed distribution using the Wilcoxon matched pair signed rank test. We used the McNemar's test to compare discrete variables. 


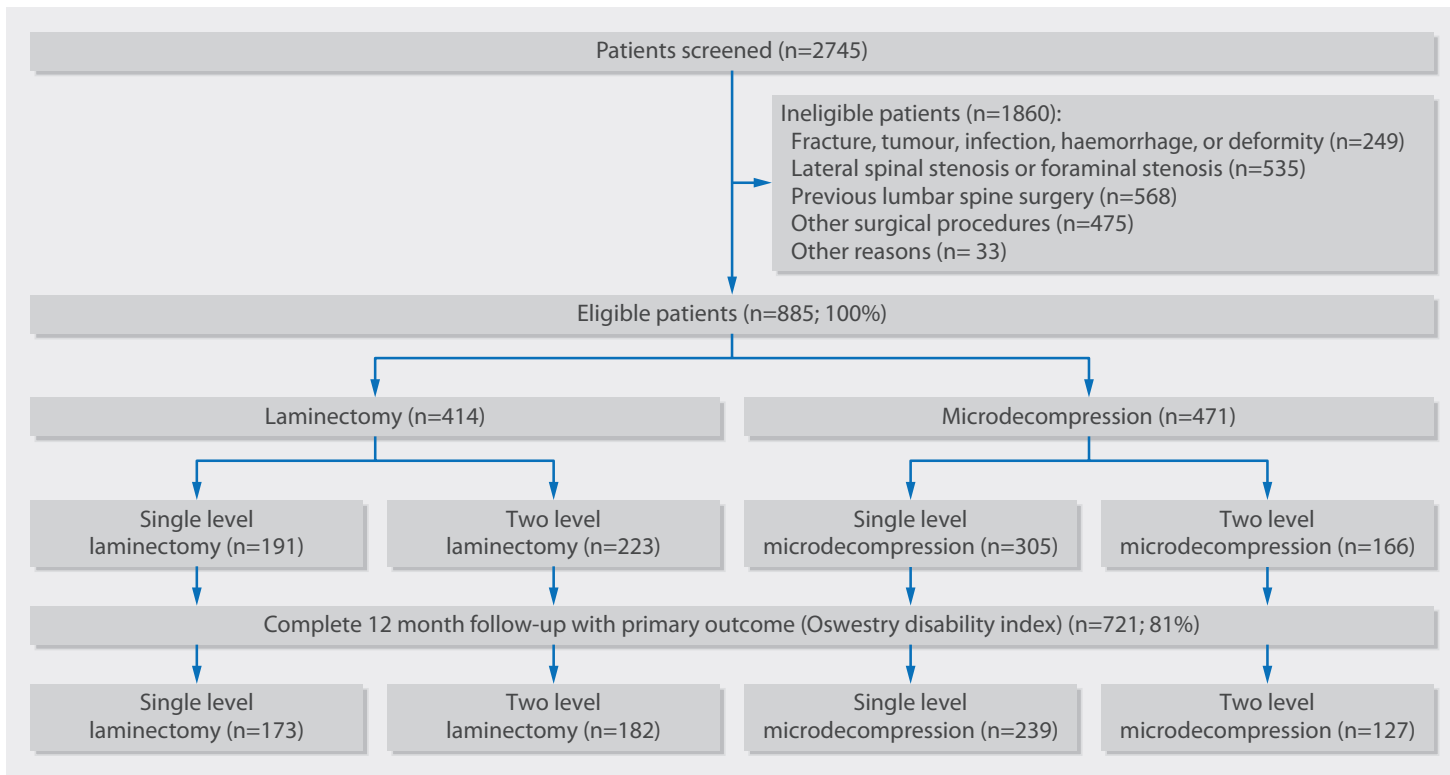

Fig 1 | Flow diagram with study enrolment and follow-up

\section{Results}

Baseline characteristics

Figure 1 shows the inclusion and exclusion process leading to 885 eligible patients, 414 of whom had laminectomy and 471 microdecompression. Participants underwent surgery at 34 orthopaedic or neurosurgical departments in 32 hospitals in Norway. Baseline characteristics were stratified by treatment groups and by matching (table 1). In the aggregate cohort there were statistically significant differences between the two treatment groups for baseline characteristics such as age, life partner, educational level, body mass index, American Society of Anesthesiologists grade, mean baseline Oswestry disability index score, and mean baseline EQ-5D score. After propensity score matching (246 pairs), these differences in baseline characteristics disappeared. In the aggregate cohort the dropout rate at one year follow-up was $14.3 \%(n=59)$ in the laminectomy group and $22.3 \%(n=105)$ in the microdecompression group $(\mathrm{P}=0.002)$. The only differences in baseline characteristics between responders and non-responders at one year were smoking $(25.5 \% \mathrm{v}$ $16.2 \%, \mathrm{P}=0.004)$, life partner ( $83.1 \% v 77.2 \%, \mathrm{P}=0.044)$, and preoperative EQ-5D (mean difference -0.085 , 95\% confidence interval -0.143 to $-0.027, \mathrm{P}=0.004)$. In the propensity matched cohort the dropout rate in the

Table 1 | Personal characteristics, coexisting illnesses, and measures of health status for both treatment groups in aggregate and propensity matched cohorts. Values are numbers (percentages) unless stated otherwise

\begin{tabular}{|c|c|c|c|c|c|c|}
\hline \multirow[b]{2}{*}{ Variables } & \multicolumn{2}{|l|}{ Aggregate cohort } & \multirow[b]{2}{*}{$P$ value } & \multicolumn{2}{|c|}{ Propensity matched cohort } & \multirow[b]{2}{*}{ Pvalue } \\
\hline & $\begin{array}{l}\text { Laminectomy group } \\
(\mathrm{n}=414)\end{array}$ & $\begin{array}{l}\text { Microdecompression } \\
\text { group }(n=471)\end{array}$ & & $\begin{array}{l}\text { Laminectomy group } \\
(n=246)\end{array}$ & $\begin{array}{l}\text { Microdecompression } \\
\text { group }(n=246)\end{array}$ & \\
\hline Age (years) & 70.1 & 66.6 & $<0.001$ & 69.1 & 68.0 & 0.113 \\
\hline Female sex & $205(49.5)$ & $222(47.1)$ & 0.479 & $116(47.2)$ & $103(41.9)$ & 0.267 \\
\hline Married or partner & $282(68.1)$ & $353(74.9)$ & 0.024 & $177(72.0)$ & $183(73.6)$ & 0.762 \\
\hline Attended college & $75(18.1)$ & $133(28.2)$ & $<0.001$ & $53(21.5)$ & $52(21.1)$ & 1.000 \\
\hline Body mass index & 28.1 & 27.2 & 0.005 & 27.5 & 27.7 & 0.968 \\
\hline Current smoker & $80(19.3)$ & $120(25.5)$ & 0.034 & $59(24.0)$ & $59(24.0)$ & 1.000 \\
\hline Comorbidity & $223(53.9)$ & $264(56.1)$ & 0.514 & $139(56.5)$ & $129(52.4)$ & 0.430 \\
\hline ASA grade $>2$ & 116 & 100 & 0.024 & 72 & 54 & 0.076 \\
\hline Preoperative ODI score & 42.5 & 38.6 & $<0.001$ & 40.5 & 40.0 & 0.820 \\
\hline Preoperative EQ-5D & 0.33 & 0.38 & 0.046 & 0.35 & 0.34 & 0.912 \\
\hline \multicolumn{7}{|l|}{ Preoperative diagnostic imaging: } \\
\hline MRI & 395 & 463 & 0.013 & $233(94.7)$ & $241(98.0)$ & 0.096 \\
\hline CT & 46 & 22 & $<0.001$ & $28(11.4)$ & $11(4.5)$ & 0.007 \\
\hline Severity of stenosis $(n=162)$ : & 62 & 98 & & 28 & 46 & \multirow{5}{*}{0.317} \\
\hline A & 1 & 0 & \multirow{4}{*}{0.324} & 1 & 0 & \\
\hline B & 12 & 12 & & 5 & 6 & \\
\hline C & 33 & 54 & & 15 & 21 & \\
\hline $\mathrm{D}$ & 16 & 32 & & 7 & 19 & \\
\hline
\end{tabular}


laminectomy group was $12.2 \%(\mathrm{n}=30)$ and in the microdecompression group was $22.8 \% \quad(n=56)$ $(\mathrm{P}=0.006)$. In the aggregate cohort the use of operating microscopes was 100\% $(n=471)$ in the microdecompression group and $39.4 \%(n=163)$ in the laminectomy group $(\mathrm{P}<0.001)$.

\section{Diagnostic imaging}

All patients underwent preoperative diagnostic imaging with magnetic resonance imaging or computed tomography. Most patients in both treatment groups underwent preoperative magnetic resonance imaging, but patients in the laminectomy group were more likely to have preoperative investigations with computed tomography both in the aggregate and in the propensity matched cohorts (table 1). In all patients from the seven hospitals in central Norway regional health authority morphological grading of stenosis was performed with a preoperative magnetic resonance imaging $(n=162)$. The groups did not differ (table 1).

\section{Primary outcome}

Among the 721 patients (81\%) with complete one year follow-up, $70.5 \%(n=508)$ achieved a minimal clinically important difference predefined as an improvement of eight points or more in Oswestry disability index score from baseline. For both groups combined the mean Oswestry disability index score at baseline was 40.0 and at one year follow-up was 22.2 (difference 17.79, 95\% confidence interval 16.47 to 19.11, $\mathrm{P}<0.001$ ).

Figure 2 shows the primary outcomes in the aggregate and propensity matched cohorts during one year of follow-up. Table 2 presents the primary outcomes of both complete case analyses and mixed linear models for the aggregate and propensity matched cohorts. In the complete case analysis for the aggregate cohort the mean difference between groups at one year follow-up was 1.3 (95\% confidence interval -1.35 to $3.92, \mathrm{P}<0.001$ for equivalence). In the propensity matched cohort the mixed linear model showed a mean reduction in Oswestry disability index score at one year follow-up of 16.0 in the laminectomy group and 19.0 in the microdecompression group. The difference between groups of 3.0 points (95\% confidence interval 0.41 to 5.58 ) was significant $(\mathrm{P}=0.023)$. However, the difference was smaller than the eight points that the study was designed to detect, and equivalence between the two treatment groups thus remained significant $(\mathrm{P}<0.001)$.

\section{Secondary outcomes}

Overall, regardless of surgical technique, there was a significant improvement in EQ-5D index score from baseline to one year follow-up, from 0.38 to 0.67 $(\mathrm{P}<0.001)$. This represents a large clinical change, with an effect size of 0.98 . Table 2 presents the changes in EQ-5D index score after one year follow-up for laminectomy and microdecompression. No statistically significant differences between treatment groups were found in either cohort regardless of model used.

Table 3 provides details of surgical treatments, duration of procedures, length of hospital stays, and complications. After propensity score matching, differences in number of levels decompressed (single level or two level decompression) and distribution of anatomical levels decompressed (L2/L3 to L5/S1) were no longer statistically significant between the groups. The duration of sur-
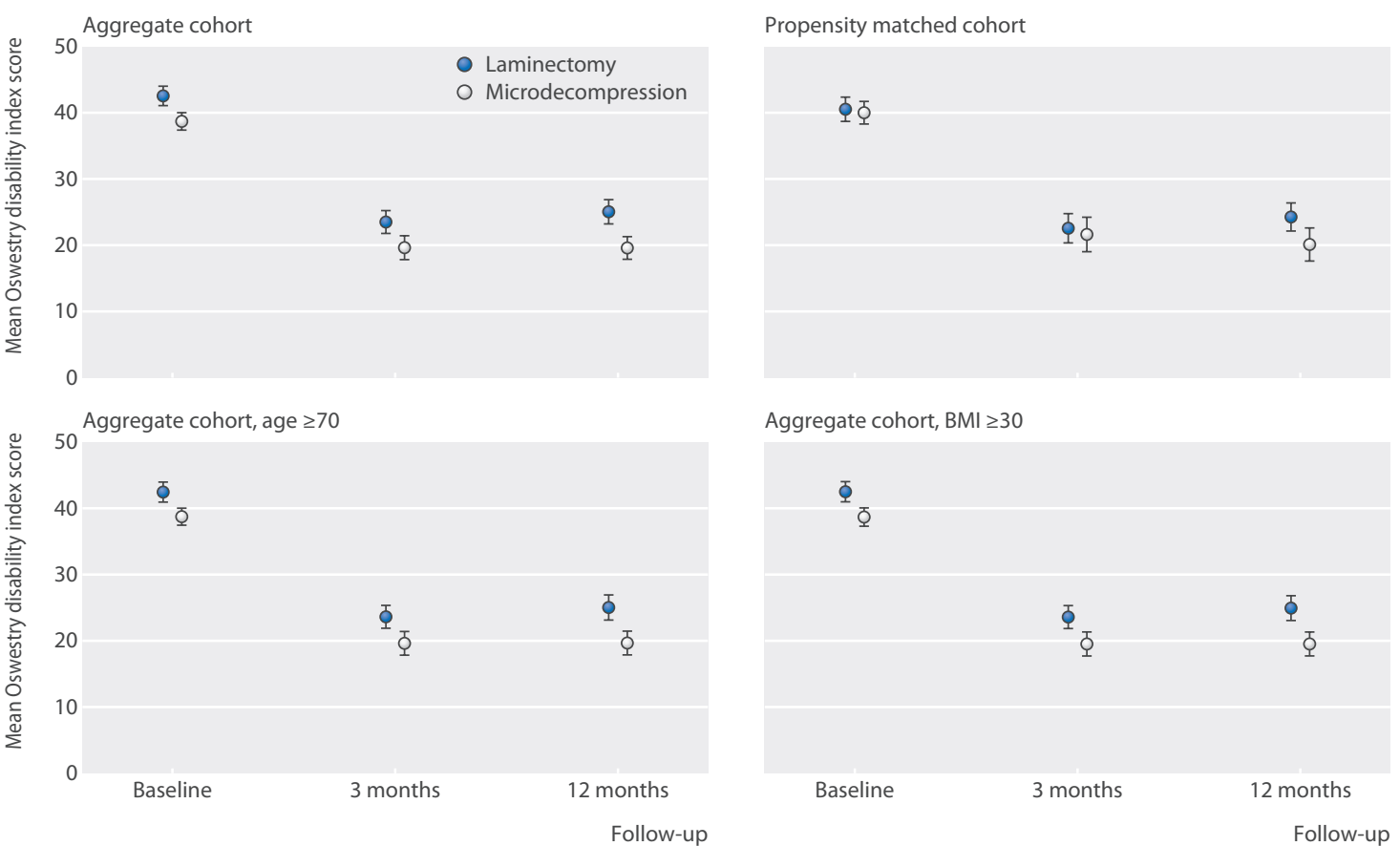

Fig 2 | Change in Oswestry disability index score after laminectomy and microdecompression for central stenosis of lumbar spine in aggregate and propensity matched cohorts during one year of follow-up. Error bars represent $95 \%$ confidence intervals. $\mathrm{BMI}=$ body mass index 


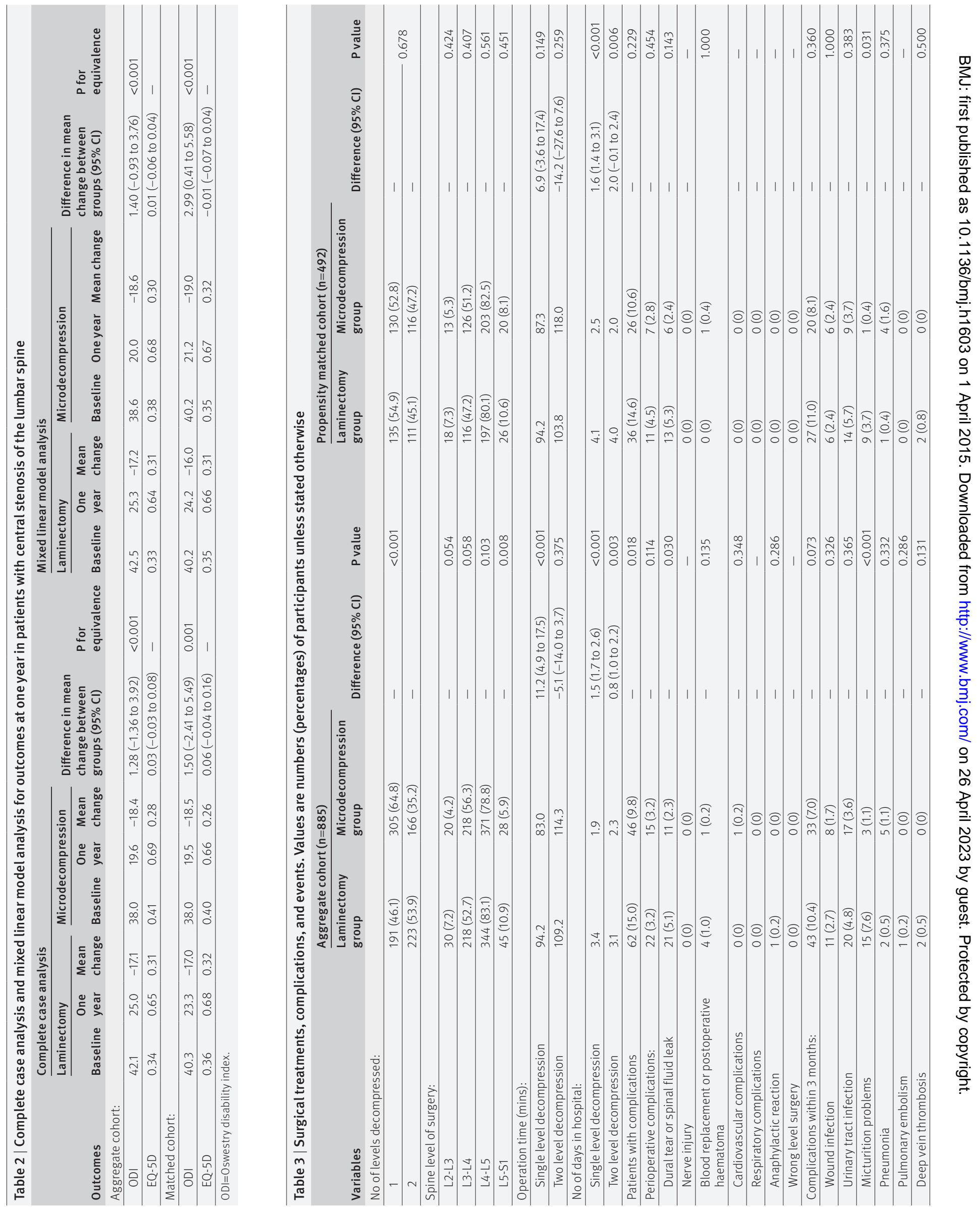


gery for single level decompression was shorter in the microdecompression group (difference 11.2 minutes, 95\% confidence interval 4.9 to $17.5, \mathrm{P}<0.001)$, but after propensity matching the groups did not differ $(\mathrm{P}=0.15)$.

The microdecompression group had shorter hospital stays than the laminectomy group both in the aggregate and in the propensity matched cohorts. In the propensity matched cohort the mean duration of hospital stays were 1.6 (95\% confidence interval 1.4 to $3.1, \mathrm{P}<0.001$ ) and 2.0 ( -0.1 to $2.4, \mathrm{P}=0.006$ ) days longer in the laminectomy group for single level and two level decompressions, respectively.

The proportion of patients with one or more complications (both surgeon and patient reported) was 12.2\% $(\mathrm{n}=108)$. The number of patients experiencing complications was significantly higher in the laminectomy group (15.0\% v 9.8\%, $\mathrm{P}=0.018)$, but after propensity matching the groups were equal $(14.6 \% v 10.6 \%, \mathrm{P}=0.23)$.

\section{Planned subgroup analyses}

Complete case and mixed linear model analyses were performed in the aggregate cohort. Figure 2 and table 4 present the results for elderly patients ( $\geq 70$ years, $\mathrm{n}=425$ ) and obese patients (body mass index $\geq 30$, $\mathrm{n}=210$ ). In elderly patients there were no statistically significant differences between the groups in Oswestry disability index or EQ-5D changes one year after surgery, and equivalence between treatment groups was found in both complete case and mixed linear model analyses. In obese patients there were no differences in Oswestry disability index or EQ-5D changes one year after surgery between the groups. There was a trend towards equivalence in Oswestry disability index change one year after surgery between the groups.

\section{Post hoc analyses}

The departments providing patients were not used as variables in the predefined statistical analyses. In a propensity matched cohort in which treating department (public hospital neurosurgical department, public hospital orthopaedic department, or private hospital) also was accounted for (providing 157 patients in each group), the mixed linear model showed mean reduction in Oswestry disability index score at one year follow-up of 18.3 in the microdecompression group and 18.1 in the laminectomy group (mean difference 0.20 , 95\% confidence interval -3.09 to $3.64, \mathrm{P}<0.001$ for equivalence).
Some departments were in transition from laminectomy to microdecompression during the study period, representing possible bias. Change in Oswestry disability index score during the first two years did not differ between the groups (laminectomy 98, microdecompression 39, difference $2.17,95 \%$ confidence interval -4.86 to 9.19, $\mathrm{P}=0.54$ ) or final two years (laminectomy 162, microdecompression $268,-1.96,-5.49$ to $1.57, \mathrm{P}=0.275)$. The microdecompression group had shorter hospital stays during both the first two years (laminectomy 78, microdecompression $43,1.5$ days, 0.4 to $2.2, \mathrm{P}=0.006$ ) and the final two years (laminectomy 155, microdecompression 297, 1.8 days, 1.4 to 2.23, $\mathrm{P}<0.001)$.

\section{Discussion}

The effectiveness of microdecompression was equivalent to laminectomy in the surgical treatment for central stenosis of the lumbar spine in this registry based multicentre observational study. This finding was consistent in both unmatched and propensity matched populations. A small difference in favour of microdecompression was seen in the primary outcome variable (change in Oswestry disability index score after one year) in a mixed linear model analysis of the propensity matched cohort. However, this difference of three points was smaller than the minimal clinically important difference of eight points that the study was designed to detect. Neither of the planned subgroup analyses in elderly and obese patients showed a difference between microdecompression and laminectomy. For elderly patients equivalence was demonstrated.

In accordance with previous observational studies, 51015 secondary outcome analyses showed a major improvement in health related quality of life measured by EQ-5D in both treatment groups. Although results at one year were strikingly similar, patients in the microdecompression group had shorter hospital stays than patients who underwent laminectomy. This finding was consistent using different strategies for analysing data. A likely explanation is that microdecompression decreases surgical trauma, allowing earlier mobilisation after surgery. However, it is also possible that surgical units adapting to minimal invasive techniques may be prone towards shorter hospital stays, having different routines for postoperative mobilisation, pain management, and hospital discharge.

\begin{tabular}{|c|c|c|c|c|c|c|c|c|}
\hline \multirow[b]{2}{*}{ Variables } & \multicolumn{2}{|c|}{$\begin{array}{l}\text { Complete case analysis } \\
\text { (aggregate cohort) }\end{array}$} & \multirow{2}{*}{$\begin{array}{l}\text { Difference in mean } \\
\text { change between } \\
\text { groups }\end{array}$} & \multirow[b]{2}{*}{$\begin{array}{l}\text { P for } \\
\text { equivalence }\end{array}$} & \multicolumn{2}{|c|}{$\begin{array}{l}\text { Mixed linear model analysis } \\
\text { (aggregate cohort) }\end{array}$} & \multirow{2}{*}{$\begin{array}{l}\text { Difference in mean } \\
\text { change between } \\
\text { groups }\end{array}$} & \multirow[b]{2}{*}{$\begin{array}{l}\text { P for } \\
\text { equivalence }\end{array}$} \\
\hline & $\begin{array}{l}\text { Laminectomy } \\
\text { group }\end{array}$ & $\begin{array}{l}\text { Microdecompression } \\
\text { group }\end{array}$ & & & $\begin{array}{l}\text { Laminectomy } \\
\text { group }\end{array}$ & $\begin{array}{l}\text { Microdecompression } \\
\text { group }\end{array}$ & & \\
\hline \multicolumn{9}{|c|}{ Body mass index $\geq 30$ : } \\
\hline ODI & -15.8 & -12.6 & $-3.24(-8.69$ to 2.22$)$ & 0.043 & -15.8 & -12.6 & $-3.24(-8.18$ to 1.71$)$ & 0.030 \\
\hline EQ-5D & 0.26 & 0.23 & $0.03(-0.09$ to 0.15$)$ & & 0.26 & 0.23 & $0.03(-0.07$ to 0.13$)$ & - \\
\hline \multicolumn{9}{|c|}{ Age $\geq 70$ years: } \\
\hline ODI & -17.2 & -18.5 & $1.28(-2.78$ to 5.33$)$ & $<0.001$ & -17.2 & -18.5 & $1.28(-2.43$ to 4.99$)$ & $<0.001$ \\
\hline EQ-5D & 0.31 & 0.28 & $0.023(-0.06$ to 0.11$)$ & - & 0.30 & 0.29 & $0.008(-0.07$ to 0.09$)$ & - \\
\hline
\end{tabular}

$\mathrm{ODI}=$ Oswestry disability index. 
Since the effectiveness of the procedures seems equivalent, it could be argued that treatment preferences should be based on the safety of procedures. The proportion of patients having durotomies and complications overall was significantly higher in the laminectomy group, but this difference did not remain after propensity score matching. However, patients in the laminectomy group were more likely to report micturition problems within three months after surgery. Degenerative spondylosis is usually a continuous process and although we found no difference at one year, a longer follow-up may be warranted to detect the effect of the two procedures on progression of spondylosis.

Novel techniques in spine surgery are often widely implemented without adequate scientific evidence backing effectiveness and safety. To our knowledge no sufficiently powered prospective studies have compared the clinical outcomes of open laminectomy versus microdecompression for stenosis of the lumbar spine. In a randomised controlled trial, microdecompression was shown to be a promising treatment alternative compared with laminectomy. ${ }^{15}$ However, there were only 40 patients in each treatment arm. As minimally invasive techniques become more widely adopted, large clinical registries such as NORspine allow the effectiveness and safety of these procedures to be monitored, evaluated, and refined. The best available evidence supporting surgical treatment of stenosis of the lumbar spine is the SPORT trial, a randomised controlled trial with a concurrent observational cohort. ${ }^{10}$ The improvement in Oswestry disability index score in our study is slightly lower than that achieved in patients undergoing decompressive surgery in the SPORT trial (17.8 $v 21.4$ points). Higher baseline Oswestry disability index scores in the SPORT trial are possibly part of the explanation, as these have a strong impact on outcomes after surgery. ${ }^{31}$

The incidence and prevalence of symptomatic stenosis of the lumbar spine are not fully established, but it has been reported that leg pain in the setting of low back pain affects $12-21 \%$ of older adults. ${ }^{32} 33$ Management of the stenosis has broad medical relevance, with a large industry evolving around the different treatment options. The rate of surgery for lumbar spinal stenosis per 100000 US Medicare beneficiaries aged 65 years or older was 135.5 in $2007 .{ }^{34}$ For many non-surgical approaches such as physical exercises, patient education, physiotherapy, lumbar corsets, and analgesic treatment there are no high quality trials to assess efficacy in the management of lumbar spinal stenosis. ${ }^{2}$ A recent study showed that the common practice of epidural injections provided no benefit in the management of lumbar spinal stenosis. ${ }^{35} \mathrm{In}$ addition to implementing minimally invasive surgery, some surgeons have shifted towards more complex fusion procedures for lumbar spinal stenosis believing this will improve stability and long term outcomes. This trend is backed by scarce evidence, and complex procedures are generally more invasive and can involve greater risks of complications and longer hospital stays, which in turn lead to higher healthcare costs. ${ }^{34} 36$ In light of our favourable results, upfront decompression and fixation in patients without spondylolisthesis may seem overly aggressive. ${ }^{34} 37$ If there are concerns about later instability we believe that surgeons should choose from the minimal invasive spectrum of decompressive procedures. Microdecompression consistently shows good clinical results, now adding equivalence to laminectomy at one year follow-up and a beneficial risk profile. ${ }^{14}$ Theoretically, microdecompression may also induce less postoperative instability ${ }^{38}$ and reduce the need for later spinal instrumentation.

\section{Strengths and limitations of this study}

The major strengths of this study are the pragmatic study design based on prospective registry data in an everyday clinical setting, large sample size, re-evaluation of preoperative magnetic resonance imaging in a large subgroup, and protocol based statistical analyses with blinded assessment of main outcome measures. The main limitation was the lack of randomised treatment allocation. Although propensity score matching adjusts for known interactions, while unlikely, residual or introduction of confounding cannot be ruled out. Another weakness was the loss to follow-up of $19 \%$ of participants regarding Oswestry disability index scores at 12 months. A previous study on a similar population from the NORspine registry showed no difference in outcomes between responders and non-responders. ${ }^{39}$

\section{Conclusion}

The effectiveness of microdecompression is equivalent to laminectomy in the surgical treatment of central stenosis of the lumbar spine. Favourable outcomes were observed at one year in both treatment groups.

\section{AUTHOR AFFILIATIONS}

'Department of Neurosurgery, St Olavs University Hospital, Trondheim, Norway

${ }^{2}$ Department of Neuroscience, Norwegian University of Science and Technology, Trondheim, Norway

${ }^{3}$ Department of Neurosurgery, Sahlgrenska University Hospital, Gothenburg, Sweden

${ }^{4}$ National Advisory Unit in Ultrasound and Image-Guided Surgery, St Olavs University Hospital, Trondheim, Norway

${ }^{5}$ National Advisory Unit on Spinal Surgery Center for Spinal Disorders, St Olavs University Hospital, Trondheim, Norway

${ }^{6}$ Department of Orthopaedics, Innlandet Hospital Trust, Brumunddal, Norway

${ }^{7}$ Department of Neurosurgery, University Hospital of Northern Norway, Tromsø, Norway

${ }^{8}$ The Norwegian National Registry for Spine Surgery, University Hospital of Northern Norway, Troms $\varnothing$, Norway

?Unit for Applied Clinical Research, Norwegian University of Science and Technology, Trondheim, Norway

${ }^{10}$ Department of Endocrinology, St Olavs University Hospital, Trondheim, Norway

${ }^{11}$ Norwegian Centre of Competence in Deep Brain Stimulation for Movement Disorders, St Olavs University Hospital, Trondheim, Norway

We thank the Norwegian Registry for Spine Surgery (NORspine). The registry receives funding from the University of Northern Norway and Norwegian health authorities. We thank all patients and spine surgeons who participate in NORspine registration.

Contributors: All authors read and approved the final manuscript. SG is the guarantor and originally conceived the study. USN and SG were involved in the study design, collection of data, statistical analysis, and writing of the manuscript. ASJ, ØS, and SMC took part in the study design, statistical analysis, and writing of the manuscript. 
OS and ØPN contributed to the study design and writing of the manuscript. CW, VR, GL, and TKS participated in the collection of data and writing of the manuscript.

Funding: This study received a grant (for quality improvement and patient safety) from the Norwegian Medical Association (www. legeforeningen.no). The funders had no role in the study design, data collection and analysis, decision to publish, or preparation of the manuscript.

Competing interests: All authors have completed the ICMJE uniform disclosure form at www.icmje.org/coi_disclosure.pdf and declare: all authors had financial support from the Norwegian Medical Association for the submitted work; no financial relationships with any organisations that might have an interest in the submitted work in the previous three years; no other relationships or activities that could appear to have influenced the submitted work.

Ethical approval: This study was approved by the regional committee for medical research in central Norway (ID2013/643) and all participants provided written informed consent. The Data Inspectorate of Norway approved the registry protocol.

Data sharing: No additional data available.

Transparency: The lead author (SG) affirms that this manuscript is an honest, accurate, and transparent account of the study being reported; that no important aspects of the study have been omitted; and that any discrepancies from the study as planned have been explained.

This is an Open Access article distributed in accordance with the Creative Commons Attribution Non Commercial (CC BY-NC 4.0) license, which permits others to distribute, remix, adapt, build upon this work non-commercially, and license their derivative works on different terms, provided the original work is properly cited and the use is non-commercial. See: http://creativecommons.org/licenses/ by-nc/4.0/.

1 Suri P, Rainville J, Kalichman L, et al. Does this older adult with lower extremity pain have the clinical syndrome of lumbar spinal stenosis? JAMA 2010:304:2628-36.

2 Katz JN, Harris MB. Clinical practice. Lumbar spinal stenosis. N Engl) Med 2008;358:818-25.

3 Amundsen T, Weber H, Nordal HJ, et al. Lumbar spinal stenosis: conservative or surgical management?: a prospective 10-year study. Spine (Phila Pa 1976) 2000;25:1424-35; discussion 1435-6.

4 Atlas S), Keller RB, Wu YA, et al. Long-term outcomes of surgical and nonsurgical management of lumbar spinal stenosis: 8 to 10 year results from the maine lumbar spine study. Spine (Phila Pa 1976) 2005;30:936-43

5 Jakola AS, Sorlie A, Gulati S, et al. Clinical outcomes and safety assessment in elderly patients undergoing decompressive laminectomy for lumbar spinal stenosis: a prospective study. BMC Surg 2010;10:34.

6 Atlas SJ, Keller RB, Robson D, et al. Surgical and nonsurgical management of lumbar spinal stenosis: four-year outcomes from the maine lumbar spine study. Spine (Phila Pa 1976) 2000;25:556-62

7 Benoist $M$. The natural history of lumbar degenerative spinal stenosis. Joint Bone Spine 2002;69:450-7.

8 Simotas AC, Dorey FJ, Hansraj KK, et al. Nonoperative treatment fo lumbar spinal stenosis. Clinical and outcome results and a 3-year survivorship analysis. Spine (Phila Pa 1976) 2000;25:197-203; discussions 203-4.

9 Malmivaara A, Slatis P, Heliovaara M, et al. Surgical or nonoperative treatment for lumbar spinal stenosis? A randomized controlled trial. Spine 2007:32:1-8.

10 Weinstein JN, Tosteson TD, Lurie JD, et al. Surgical versus nonsurgical therapy for lumbar spinal stenosis. N Engl J Med 2008;358:794-810

11 Deyo RA. Treatment of lumbar spinal stenosis: a balancing act. Spine / 2010;10:625-7.

12 Ciol MA, Deyo RA, Howell E, et al. An assessment of surgery for spinal stenosis: time trends, geographic variations, complications, and reoperations. J Am Geriatr Soc 1996;44:285-90.

13 Gunzburg R, Szpalski M. The conservative surgical treatment of lumbar spinal stenosis in the elderly. Eur Spine ) 2003;12(Supp 2):S176-80.

14 Smith ZA, Fessler RG. Paradigm changes in spine surgery: evolution of minimally invasive techniques. Nat Rev Neuro 2012;8:443-50.
15 Thome C, Zevgaridis D, Leheta O, et al. Outcome after less-invasive decompression of lumbar spinal stenosis: a randomized comparison of unilateral laminotomy, bilateral laminotomy, and laminectomy. I Neurosurg Spine 2005;3:129-41.

16 Barkun JS, Aronson JK, Feldman LS, et al. Evaluation and stages of surgical innovations. Lancet 2009;374:1089-96.

17 Von Elm E, Altman DG, Egger M, et al. The Strengthening the Reporting of Observational Studies in Epidemiology (STROBE) statement: guidelines for reporting observational studies. Lancet 2007:370(9596):1453-7.

18 Nerland US, Jakola AS, Solheim O, et al. Comparative effectiveness of microdecompression and laminectomy for central lumbar spinal stenosis: study protocol for an observational study. BMJ Open 2014; 4:e004651.

19 Fairbank JC, Couper J, Davies JB, O'Brien JP. The Oswestry low back pain disability questionnaire. Physiotherapy 1980;66:271-3.

20 Grotle M, Brox JI, Vollestad NK. Cross-cultural adaptation of the Norwegian versions of the Roland-Morris Disability Questionnaire and the Oswestry Disability Index. J Rehabil Med 2003;35:241-7.

21 Solberg TK, Olsen IA, Ingebrigtsen T, et al. Health-related quality of life assessment by the EuroQol-5D can provide cost-utility data in the field of low-back surgery. Eur Spine J 2005;14:1000-7.

22 Schizas C, Theumann N, Burn A, et al. Qualitative grading of severity of lumbar spinal stenosis based on the morphology of the dural sac on magnetic resonance images. Spine (Phila Pa 1976) 2010;35:1919-24.

23 R Development Core Team. R A language and environment for statistical computing. R Foundation for Statistical Computing, 2007.

24 Brox JI, Reikeras O, Nygaard O, et al. Lumbar instrumented fusion compared with cognitive intervention and exercises in patients with chronic back pain after previous surgery for disc herniation: a prospective randomized controlled study. Pain 2006;122:145-55.

25 Hellum C, Johnsen LG, Storheim K, et al. Surgery with disc prosthesis versus rehabilitation in patients with low back pain and degenerative disc: two year follow-up of randomised study. BMJ 2011;342:d2786.

26 Knutsson B, Michaelsson K, Sanden B. Obesity is associated with inferior results after surgery for lumbar spinal stenosis: a study of 2633 patients from the Swedish spine register. Spine (Phila Pa 1976) 2013;38:435-41.

27 Twisk J, de Boer M, de Vente W, et al. Multiple imputation of missing values was not necessary before performing a longitudinal mixed-model analysis. J Clin Epidemiol 2013;66:1022-8.

28 Kazis LE, Anderson JJ, Meenan RF. Effect sizes for interpreting changes in health status. Med Care 1989;27(3 Suppl):S178-89.

29 Hemmila MR, Birkmeyer NJ, Arbabi S, et al. Introduction to propensity scores: a case study on the comparative effectiveness of laparoscopic vs open appendectomy. Arch Surg 2010;145:939-45.

30 Austin PC, Grootendorst P, Anderson GM. A comparison of the ability of different propensity score models to balance measured variables between treated and untreated subjects: a Monte Carlo study. Stat Med 2007;26:734-53.

31 Pearson A, Lurie J, Tosteson T, et al. Who should have surgery for spinal stenosis? Treatment effect predictors in SPORT. Spine (Phila Pa 1976) 2012;37:1791-802

32 Hicks GE, Gaines JM, Shardell M, et al. Associations of back and leg pain with health status and functional capacity of older adults: findings from the retirement community back pain study. Arthritis Rheum 2008;59:1306-13.

33 Vogt MT, Cawthon PM, Kang JD, et al. Prevalence of symptoms of cervical and lumbar stenosis among participants in the Osteoporotic Fractures in Men Study. Spine (Phila Pa 1976) 2006;31:1445-51.

34 Deyo RA, Mirza SK, Martin BI, et al. Trends, major medical complications, and charges associated with surgery for lumbar spinal stenosis in older adults. JAMA 2010;303:1259-65.

35 Friedly JL, Comstock BA, Turner JA, et al. A randomized trial of epidural glucocorticoid injections for spinal stenosis. N Engl J Med 2014;371:11-21

36 Ong KL, Auerbach JD, Lau E, et al. Perioperative outcomes, complications, and costs associated with lumbar spinal fusion in older patients with spinal stenosis and spondylolisthesis. Neurosurg Focus 2014;36:E5

37 Deyo RA, Nachemson A, Mirza SK. Spinal-fusion surgery-the case for restraint. N Engl / Med 2004:350:722-6.

38 Bresnahan L, Fessler RG, Natarajan RN. Evaluation of change in muscle activity as a result of posterior lumbar spine surgery using a dynamic modeling system. Spine (Phila Pa 1976) 2010;35:E761-7.

39 Solberg TK, Sorlie A, Sjaavik K, et al. Would loss to follow-up bias the outcome evaluation of patients operated for degenerative disorders of the lumbar spine? Acta Orthop 2011;82:56-63.

(C) BMJ Publishing Group Ltd 2015 